\title{
Planning in the Irish Healthcare System; Legislative Strategy or Administrative Control?
}

Vivienne Byers

Technological University Dublin, vivienne.byers@tudublin.ie

Follow this and additional works at: https://arrow.tudublin.ie/buschmanart

Part of the Health and Medical Administration Commons

\section{Recommended Citation}

Byers, V. Planning in the irish healthcare system: legislative strategy or administrative control? Journal of management and marketing in healthcare, Vol. 2, No. 1, 2008, P. 1-13. DOI: http://dx.doi.org/10.1179/

175330309791011280

This Article is brought to you for free and open access by the School of Management at ARROW@TU Dublin. It has been accepted for inclusion in Articles by an authorized administrator of ARROW@TU Dublin. For more information, please contact arrow.admin@tudublin.ie, aisling.coyne@tudublin.ie,gerard.connolly@tudublin.ie.

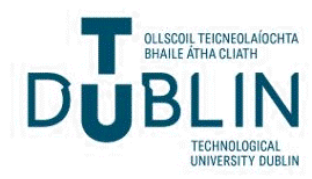


Vivienne Byers has been a researcher and lecturer in the Faculty of Business, Dublin Institute of Technology since 2000 and lectures in health services policy and planning and organisational change. She has also lectured externally on various healthcare

management courses and carried out consultancy in the health sector. She has extensive experience working as a health professional in Ireland, Canada and the UK. Her research interests lie in the field of strategic change in public services, notably health services planning, as well as in healthcare reform, comparative healthcare and the involvement of service users in planning.

Keywords: service planning, control, national health strategy, legislation, needs assessment, stakeholder representation
Q1 Vivienne Byers Faculty of Business Dublin Institute of Technology Ireland

\section{Planning in the Irish healthcare system: Legislative strategy or administrative control?}

\author{
Vivienne Byers \\ Received (in revised form): 8th June, 2008
}

\begin{abstract}
Although strategic planning in healthcare has been in evidence in many OECD countries since the 1970s, it did not emerge in Ireland until the advent of legislatively mandated service planning in the 1990s. This occurred in the context of significant managerial, organisational and environmental change. One of the central mechanisms of the Strategic Management Initiative is the devolution of accountability and responsibility from the centre to the periphery. Service planning in the health sector in Ireland is seen as part of this strategic planning ethos. This paper reports on part of a wider study that examined both the intent and the consequences of this legislatively mandated service planning and looked at the process of its implementation in Irish healthcare. This has important implications for Irish health policy due to the continuing budget overruns, the embargo on recruitment of frontline staff and the reported lack of strategic planning. This paper posits explanations for the difficulty in aligning strategy and planning after nearly a decade of service planning.
\end{abstract}

\section{Introduction}

According to Mary Harney, the Irish Minister for Health and Children, the OECD has confirmed that Irish spending on health has gone from 15 per cent below the OECD average to 17 per cent above in the period 1997-2003. ${ }^{1}$ The 2008 allocation of over $€ 16 \mathrm{bn}$ for the health services was announced in December 2007, an increase of 9 per cent on the previous year's figure. ${ }^{2,3}$ Public demand for further financial resources to be put into the health services still remains strident, but since 2002, commentators have increasingly questioned the use of the resources already invested. ${ }^{4,5}$ That the health services need to be strategically planned is not in doubt, as a review of the Irish healthcare system indicates that the commitment of state resources to the health sector has increased over time to the point where this segment accounts for one of the largest items of public expenditure. ${ }^{6,7}$ Public debate has raged over the need to catch up and maintain the average EU health spend; however, such increases have not alleviated what is seen as a crisis in the Irish healthcare system. ${ }^{8,9}$ There also remains the problem of the transparency of the health spend itself. ${ }^{10}$ Publicly, there has been much debate over the 
value for money that the health services should be offering given the financial resources invested.

In the early 1990s, there were serious overruns in budgetary spending by a number of healthcare organisations. Concern regarding expenditure from the Department of Finance was communicated to the Department of Health and Children (DOHC) and the need for budgetary control was placed high on the agenda. In 1994, the Strategic Management Initiative ${ }^{11}$ placed strategic planning of services firmly in the public sector sphere. The 1994 health strategy, Shaping a Healthier Future, ${ }^{12}$ and the resulting service planning legislation in 1996 was the DOHC's response; a new era was to begin. A gradual shift towards increased accountability and transparency, and improving equity and quality in the Irish healthcare system had begun to emerge.

\section{The Irish healthcare system}

The Government, the Minister for Health and Children and the DOHC are at the head of health service provision in Ireland. This health service provision is publicly funded through taxation. Until 2005 (the period of this research), the Irish healthcare sector comprised a health board management structure, 11 health boards in all, and was described as an integrated public healthcare system. The boards were the main providers of health and personal social care at a regional level. Health boards were composed of elected local representatives, ministerial nominees and representatives of health professions employed by the board. The legislation implementing service planning applied across all the health boards. The Irish health services are not universally free; only about onethird of the population have medical cards entitling them to receive services free of charge (including general practitioner services). In the main, everyone has coverage for public hospital services with some modest charges, and some personal and social services. Over half the population has private health insurance. The Irish health system is presently undergoing structural reform following the establishment in 2005 of a single authority responsible for the planning and delivery of health services in Ireland, namely the Health Services Executive.

\section{Setting the scene: Legislation and strategy in Irish healthcare in the 1990s}

In the 1990s, the health strategy was the culmination of many documents outlining the importance of strategic planning for Ireland's health services. For the first time in Irish healthcare there would be a national strategy to guide the healthcare system in determining priorities and underpinning all planning in healthcare in the next four years. The proposal was to strengthen accountability and to underpin it with a multiannual strategic plan. ${ }^{13}$ This would be supported by the key principles of equity, quality and accountability. There would also be a full review of organisational and management arrangements. It was this strategy that sowed the seeds for the service planning legislation ${ }^{14}$ that put into train 
the service planning process on an annual basis, not in the form of a multi-annual strategic plan as originally proposed.

Thus, in 1998, service planning was introduced into Ireland's healthcare services to function as 'a strategic management tool'. ${ }^{15}$ The crucial link between resources and clear objectives was emphasised. However, the legislation did not appear to recognise the complexity of planning in the healthcare system. In addition, the health strategy promise to legislate for service user participation in the decision-making process also was not present. The legislation was welcomed by politicians and seen as a control and brake on health spending. It represented some changes in the framework of accountability for health services management. Its focus was to improve financial accountability and it obliged health boards to produce an annual service plan as well as to secure the 'most beneficial, effective and efficient use of resources' ${ }^{16}$ However, it was not explicit on how this was to be implemented at health board level. The assumption was that the health strategy rhetoric regarding the provision of health services that would be equitable, accountable and quality focused, planned with the participation of users and all those charged with delivering the services, would be realised through the implementation of the Act, and that the processes for that implementation would be drawn up at health board or DOHC level. In this way, there would be a disconnect between those crafting policy and those implementing it.

\section{Planning for the future: 2000 and beyond}

A second national health strategy, Quality and Fairness, ${ }^{17}$ was launched in 2001 to give strategic direction to the health services for the next 7-10 years. It outlined the DOHC's aim to make the service development and planning process a more 'sophisticated' tool for planning based on common strategic objectives and 'clear' performance indicators. It described the legislation underpinning service planning as an important milestone in achieving greater accountability regarding expenditure, and that service planning coupled with annual reports and financial statements were vital tools in the 'strategic planning' process. It went on to describe it as a 'sound framework for planning and implementing strategic policy objectives'. ${ }^{18}$ The new national health strategy was to function in terms of underpinning planning of services and guiding policy makers and service providers towards the delivery of an articulated vision. This vision was to encompass the four key principles of the new national health strategy: equity, 'people centredness', quality and accountability. The ability of the service planning process to be strategic in aligning this vision and its strategic objectives in the resulting service plans was crucial in moving this vision forward.

The health strategy also set in motion a number of significant changes that have been put in place by the Health Reform Programme. ${ }^{19}$ A new Health $\mathrm{Act}^{20}$ was enacted in 2004 and set in motion the establishment in 2005 of a single authority responsible for the planning and delivery of health services in Ireland - the new Health Services Executive. The 
accountability provisions of this legislation also specify details of the service planning process which are very similar to the 1996 legislation; it specifies that the annual service plan must 'indicate the type and volume of health and personal social services to be provided', 'indicate any capital plans proposed by the executive' and 'contain estimates of the number of employees of the executive for the period and the services to which the plans relate'.${ }^{21}$ There is also provision for the annual service plan to be underpinned by a three-year corporate plan. Whereas the health strategy endorsed the importance of local or regional service planning, the new legislation now centralises all health planning into a single 'national service plan'.

In conclusion, service planning has been in operation since 1998 and the $\mathrm{DOHC}^{22}$ initially reported its success as a strategic planning function and process. Across health boards it has been implemented by means of a standard template. Butler and Boyle ${ }^{23}$ asserted that the introduction of service planning as a tool for strategic management has helped the process of identifying service needs, reviewing performance, identifying priorities, and putting in place mechanisms for monitoring progress and evaluating effectiveness. This paper will look at its implementation up to 2005 , which does not fully reflect all the reform changes to date.

Nonetheless, the questions raised by this paper remain pertinent to the present legislation and structural arrangement.

\section{Theoretical framework}

In Mintzberg's typology, ${ }^{24,25}$ a healthcare organisation is classified as a professional bureaucracy characterised by many varied and competing groups. It relies on the skills and knowledge of the operating professionals to function and to produce standard products or services. In the rationing of resources, these professionals exercise discretion and in doing so, have considerable influence. This raises a number of issues, notably how this professional authority is controlled in the public interest. Applying legislation to plan services strategically has implications. A single integrated pattern of decisions loses a good deal of meaning in such an environment, as each group attempts to assert its own values or norms. Therefore, control of the professional bureaucracy must be based on mutual consensus or a partnership at best. Historically, according to Pettigrew, Ferlie and McKee, ${ }^{26}$ healthcare organisations are seen as highly change-resistant, in part because of the highly political nature of healthcare delivery and in part because of the highly segmented nature of the organisation as well as the special veto power of clinicians. So with respect to the Irish context, a mechanistic budget-driven framework of control as outlined in the service planning legislation is unsuited to the nature of healthcare and will be resisted by professionals. The challenge is to reconcile these efficiency objectives with effective delivery of healthcare services by professionals. One position, as advocated by McKevitt, Millar and Keogan, ${ }^{27}$ is to see that the actual management and delivery of services to the citizen is mediated through and influenced by, a complex set of professional, institutional and social 
arrangements that both influence and constrain the service delivery process. The street-level public organisation (SLPO), developed originally by McKevitt ${ }^{28}$ and adapted by Byers and McKevitt ${ }^{29}$ (see Figure 1), can account for these arrangements and is outlined below.

An understanding of planning in the health board using this model allows one to determine the capacity of the organisation to deliver on service planning as mandated by the legislation, as well as the strategy as outlined by the national health strategies. As the SLPO shows, the immediate source of recurring tension is point $\mathrm{A}$ - relations between central government and the professions. Two types of influence are in operation in the SLPO. At government level there are a number of modes of influence: legislation, allocation of resources, organisational structure and performance measurement. Then there are the 'rules of the game', which are established by the professions and their associations.

According to Millar and McKevitt, ${ }^{30}$ these conflicting influences must be aligned otherwise the activities of the SLPO will run wild and undirected. With few exceptions, the normative literature on planning in healthcare, underlines the necessity for extensive participation by health professionals, ${ }^{31,32,33}$ the main argument being that implementation will be facilitated if people feel they have been involved in decisions.

The SLPO model shows that implementing service planning and introducing strategic change is not solely an organisational issue as it has to account for control in a wider institutional context. This institutional perspective is reflected in the legislation introducing service planning. If it does not allow for strategic management processes because it does not recognise the complexity of the nexus of relationships, then problems will occur. These can be many, ranging from ambiguity in policy aims,

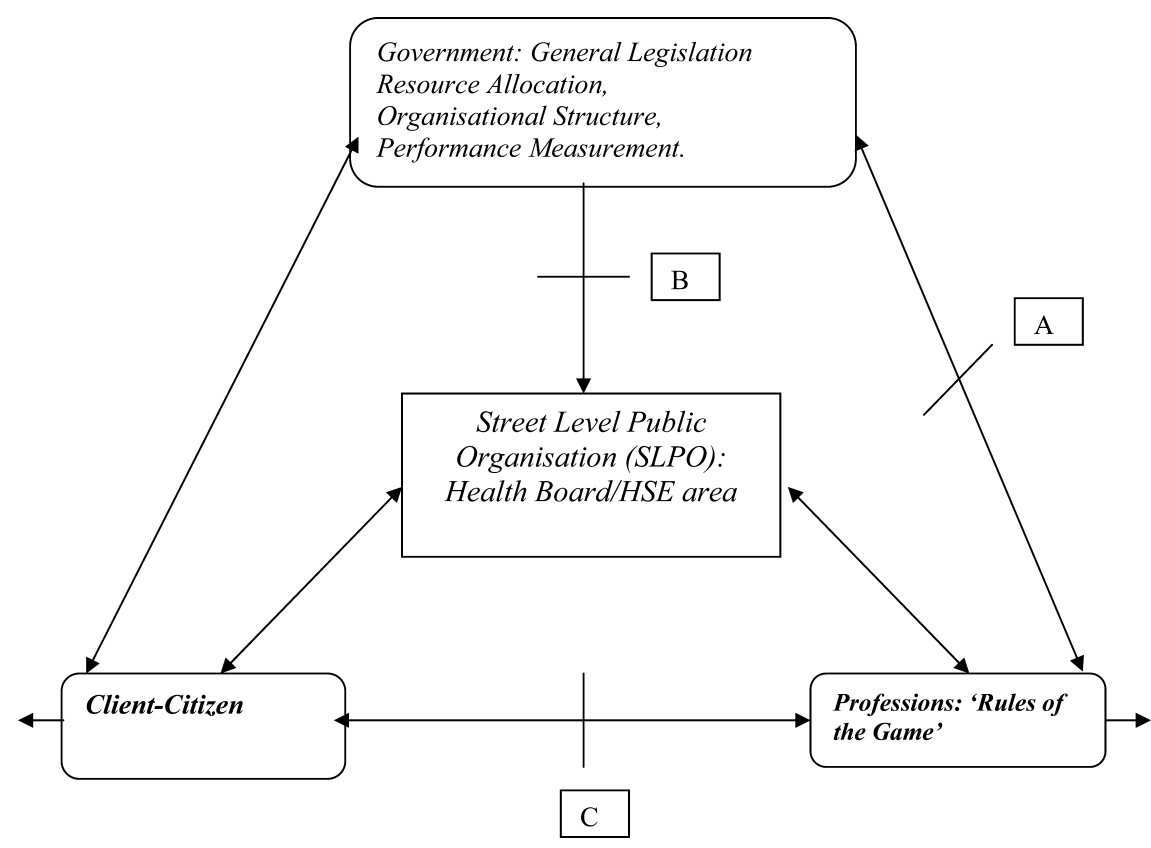

Figure 1: The street-level public organisation model — tensions in the environment 
problems in relating general guidance, enforcement, changing financial and manpower assumptions, and differing time horizons for actors (planners vs healthcare professionals).

The model of control is left at the level of budgets only, which does not control for the effectiveness of service delivery and therefore leaves the citizen-client in a weak position. As McKevitt ${ }^{34}$ notes in his original implementation of the SLPO model, any defect in the legislative framework will lead to recurring tensions between central government and professional associations (point A) in the environment of the SLPOs. If there is a solid relationship between the professions and government then these tensions can be averted. In Ireland at present, however, the debate about the healthcare crisis centres on the Government's assertion that many of the problems relate back to poor performance by the professions.

For any strategic and policy-driven shift to occur in the pattern of resource allocation (see point $\mathrm{B}$ ) there needs to be an explication of that position in the public service delivery and investment decisions legislation. Given the paucity of direction in the service planning legislation, it can be posited that the strategic direction of national health strategies to drive change will not occur, despite the rhetoric of government. Another source of tension is that between the professional and the community of citizens (see point $\mathrm{C}$ ), where the lack of central government control over the professional leads to an erosion of the community's needs and rights. As McKevitt ${ }^{35}$ points out, in Anglo-Saxon countries the prevailing culture for professionals features individualism. At times this may function to the disadvantage of the citizen-client and the community.

\section{The research}

In examining strategic control in health service delivery there is a need to acknowledge that public service managers are not themselves involved in the strategy formulation phase, which is usually the domain of the politician. ${ }^{36,37}$ However, it is the public service managers who have an important role to play in implementing legislation; their advice and interpretation of the legislation have a profound effect on the citizenclients who rely on them for effective delivery of services. This study seeks to evaluate this process of change in the implementation of service planning in the Irish healthcare system in two key areas: the intent of the legislation itself and the capacity of the system to respond to these changes.

The design of this research is what $\mathrm{Yin}^{38}$ describes as a multiple case study. The choice was made to study the dynamics of strategic change in their setting by investigating a number of health boards in the Irish context. This paper thus reports on one part of a wider comparative study. Given the structural organisation of healthcare in Ireland it became apparent that service planning should be examined at the health board level (for which three were chosen), but should also account for the wider institutional influences, ie the context in which those cases were 
situated. This wider view included looking at other stakeholder perspectives, such as government and other healthcare organisations in the healthcare system, as well as examining the legislative influence. This research was carried out over an 18-month period in 2004-05.

The legislation implementing service planning applied across all the health boards. Each of the health boards was studied by taking a vertical slice through organisations and examining the perspectives of this process from health professional (head of discipline level) up to CEO/assistant CEO level. The final number of interviewees was 36. In addition to the interview data and the literature review, an evaluation of the health legislation and policy leading up to the inception of service planning was made to determine the strategic intent and the type of control system that has developed. Using qualitative analysis of interview data, a number of core themes were identified, some of which will be outlined below.

\section{Results}

This paper has focused on one aspect of a wider comparative study of service planning in the context of significant organisational change in the Irish health sector. Two of the core themes identified in the study are briefly outlined and the SLPO model is used to assist in analysis of the data. Through this analysis, the implications for Irish healthcare planning will be described.

In reporting the findings from this study, data emerging from interviews with health professionals at middle-management level were treated separately from the data from interviews with senior management. This was due to the strong lack of cohesion in the service planning process between these levels in the hierarchy. These disparate views of the service planning process were stark and this arrangement made it easier to make sense of the data.

Looking to the function of service planning as a strategic management tool, two of the core themes that emerged in this research were needs analysis and stakeholder involvement.

\section{Determination of service levels and needs}

The issue of needs assessment (environmental assessment) was one of the core themes identified in the research. According to the majority of health professional interviewees, there was a lack of assessment of needs and service level requirements beyond budgetary criteria.

The service planning legislation is meant to facilitate the development of strategic management processes by allowing priorities identified in the health strategy to underpin service planning resource allocation decisions. The interviewees' reports of the service planning process indicated that priorities and planning were not based on an analysis of needs, but on the previous year's service plan and the limits of the budget allocation. The level of frustration evinced by the service planning process for health professionals was high. They told stories of knowing the needs and priorities of their service, and yet, they were powerless in 
the planning process. They also cited a lack of facilities with which to gather crucial data about their services and the pattern of demand and use. That an information technology deficit existed is not in doubt, it was noted by the DOHC themselves.

Management concurred that there was a lack of needs assessment. In some cases, managers expressed the view that a clean sheet review of services was not feasible or necessary. Again the focus was on the higher ranks in the hierarchy making the key decisions, and cascading them down to the frontline. In the main, they saw it is a control process based on politics from above rather than strategic thinking. Many at senior management level did not see an analysis of needs as a priority. Some expressed frustration at the political pressure brought to bear in determining service priorities and direction; others felt that the control exercised by the budget was appropriate.

Here, a theme of disconnection between the health professionals and management and those above in the DOHC arises. The health professionals felt that not only were the needs they identified for their service not being acknowledged, but they were not even sought to begin with. Many health professional interviewees expressed dissatisfaction with senior management's lack of knowledge of their service:

'There has really been no planning and we are not involved ... As I said it's all political and they don't want us to be involved but I ask who is it that understands the services. I think it's those that deliver them and we are delivering them.' (Head of Discipline - Medicine)

In the main, interviewees identified this environmental scanning and needs assessment as an important gap.

\section{Stakeholder representation}

As stakeholders in the process, the health professionals in this study expressed frustration at their needs not being heard or listened to. Control was seen to be exercised from above, with priorities being decided at either a national or senior management level. There were frequent references to 'them and us':

'We're pushed into a more operational focus - we need to be strategic. We need to be at the front - we need to have an interface with the executive - we don't have it.' (Head of Discipline — Nursing)

At a national level, relations between government and the health professions have reached an all-time low. ${ }^{39}$ In the health board system, the professionals can dictate the 'rules of the game' to some degree. This research found a number of instances where health professionals had withdrawn from the service planning process and instituted their own strategic or 'real planning' exercise.

In some areas it was acknowledged that there was difficulty in engaging with some professionals in service planning, most notably medical consultants in establishing the business directorate model. In 
that regard, the healthcare managers are powerless to define the rules of the game. However, many healthcare managers expressed the view that provided they had all the information they needed, they could plan well enough without further input from the health professionals:

'We paid lip service to involvement. It was perceived that expertise was in the core and in a perverse way that it would lead to difficulties to ask too many opinions, as you'd have too many views to deal with, right or wrong.' (Manager of Care Services)

Due to the restrictions of the process and the template, some managers felt consultation and other information was superfluous in many cases. In addition, it could lead to information overload.

Given that service planning had initially been touted as a means of devolving decision making down the ranks to the health professionals, there was understandably a lot of comment on the lack of trust that senior management had in the abilities of the health professionals. Some of this was due to the imposition of controls from above, and the isolation of the operating core from what management view as the 'real' work of planning and strategy.

A number of interviewees mentioned the lack of client representation in service planning. This was raised as an issue, due to the inclusion of consumer involvement as a heading on the new service-planning template, and yet it had not become a reality. There were some concerns about the dearth of a wider stakeholder representation at the negotiation table, but some interviewees noted that it was linked to the restrictiveness of the process in general.

\section{Discussion}

The findings reported here were examined using the SLPO model to examine the consistency between espoused service planning objectives at the national level, and their implementation at the point of service delivery. Tensions arise in reconciling the different demands in the system. A key area of tension is identified at point B. Looking at the control system, is to examine the guidance from the service planning legislation itself, otherwise, there will be no strategically-driven shift in the pattern of resource allocation. In this regard, the previously discussed needs analysis would help shift resource allocation in line with national health strategy principles. However, the research findings indicated that this was not occurring, mainly because the legislation focused on budgets.

The other sources of tension - point A, relations between central government and the professions, and point $\mathrm{C}$, relations between the professions and the community of citizen-clients - are identified and relate to the lack of stakeholder involvement in the process of service planning identified by the interviewees. Although the Irish healthcare system exemplifies a pluralist organisation, the divisions between the groupings of health professionals and management remain stark. 
Mintzberg ${ }^{40,41}$ describes how those outside the operating core in the professional bureaucracy blame its problems on the lack of external control of the professionals and their professions. The answer to these problems is to attempt to control the work of the professionals through a number of coordinating mechanisms, specifically direct supervision, standardisation of work processes or standardisation of outputs. Hence, management use a service plan and performance indicators derived mostly from their own ranks to standardise measurement and production of outputs. These measures are used mainly as a means of control. According to Jacob, ${ }^{42}$ these demands for quantification can be used to replace professional judgment.

The tension at point C in the SLPO model is that between the health professions and the community of citizen-clients, namely a natural break in relations that occurs between the professions and the citizens they serve. Professions are thus seen as self-serving and not representing their clients. In many cases, it is the professionals who are thus blamed by the public for greed or lack of services, rather than the weaknesses in the system itself, which does not serve either grouping. As an example the hospital system in Ireland is described as 'two-tiered', as public patients and private patients are in many instances both treated in the same facility. However, they both receive the services of the same medical consultant who is employed on an annual salary to treat public patients, while maintaining the right to treat private patients on a fee-for-service basis. This arrangement for the public system to benefit from close interaction with the private system actually creates perverse incentives and is inequitable in terms of access and utilisation, as the better-off have priority access. Thus, an increasing percentage of the population is taking out private health insurance while those that cannot afford to do so remain on lengthening waiting lists, and the key health strategy principle of 'equity' is undermined by government policy.

That the nexus of relationships in the SLPO is not acknowledged at the heart of service planning and delivery means that both the professional service provider who provides the professional services, and the citizen-client who is the recipient of these services is not involved in that process. That lack of involvement results in the lack of any needs and evidence-based planning. Instead, the reliance on the limits of the legislation means that service planning never evolves to anything more than a fiscal control measure.

As Maddock ${ }^{43}$ notes, public sector modernisation needs conceptual modelling. She goes on to explain how the development of social capital is better encapsulated by models that reflect the connection and dependence between forces. The SLPO model allows the researcher to focus on these complex organisations with their competing stakeholder interests. Unlike private sector organisations, the pull of the professional associations and the downward push from central government needs to be balanced to allow for the needs of the citizen-client. In addition, the model borrows from readings in the strategic management literature to allow for explanations of the introduction of such initiatives as 'New Public Management'. Two of the key themes emerging in the present 
study — the lack of needs analysis and stakeholder involvement — are accounted for through this model. The data in this study reinforce McKevitt's ${ }^{44}$ original findings that, to put it simply, publicly-funded Irish healthcare requires legislative change to clarify its strategic base and that control should be seen as an outcome of consensual management. One way to do this, as Wrigley ${ }^{45}$ opines, would be to legislate for the right to healthcare for the citizenry.

\section{Conclusion}

When choosing service planning as a focus of this research, a number of issues came to the fore, most notably that strategic planning and management are crucial to the Irish healthcare system and that, despite increased investment, the system is presently in difficulty. ${ }^{46}$ Service planning as a part of a suite of change processes in the Irish healthcare sector should be a cornerstone of change for the better. Yet, from its inception, there have been problems in implementation. Many of the participants in the process have identified key difficulties. However, when seeking solutions to any health service issue, each stakeholder has a different answer, or for that matter, list of answers. Therefore, to analyse this situation, especially with a comparative focus in the healthcare arena, one must be able to 'find the forest without losing sight of the trees'. ${ }^{47}$

This study narrowed down the conceptual framework to a number of key problems, focusing particularly on the limits of the control system, that is, the legislation itself, in terms of strategic intent. This problem has led to service planning within the Irish healthcare system to operate with a purely control focus - a financial control focus.

The service planning legislation in 1996 (and the later iteration in 2004) saw some changes in the legislative framework of accountability for health services management. Specifically, it delivered a means to control or use the influence of the state in bringing into balance the stakeholders' relationships in the delivery of healthcare services to the citizen or client. It is this service delivery to the citizen-client that should be the end goal, given that the national health strategy is replete with promises of equity, accountability, people-centredness and quality. The legislation, however, provides no outlet for these aspirations. Instead, rather than facilitating the relationships between key players in order to build up support, the findings of the study indicate that the legislation has further distanced these stakeholders. The breakdown of the relationship with the citizen-client is ultimately due to the breakdown of relationships and trust between government/management and health professionals. This is unfortunately the result of a legislative framework that does not contain an explicit strategy to guide the resource allocation process in meeting the four key principles.

In espousing the concept of strategically managing health services, a fundamental question in strategic management, according to Johnson and Scholes ${ }^{48}$ is 'what business are we in?' The present study indicates uncertainty as to whether the 'business' of healthcare is directed towards 
the provision of services for the citizen or whether it is directed towards budget control and providing services for those that can pay for them. It is thus crucial that we determine what business we are in before proceeding any further along the path of healthcare reform.

\section{References}

1. Department of Health \& Children (2005) 'Tánaiste rejects criticism that $€ 12.6 \mathrm{bn}$ in health spending is not enough', press release, 18th November.

2. Department of Finance (2007) 2008 Estimates for Public Services (Abridged Version) and Summary Public Capital Programme, Stationery Office, Dublin.

3. Department of Health \& Children (2007) 'Mary Harney, TD, Minister for Health \& Children, Announces the details of the Budget 2008 package for the health services', press release, 5th December.

4. Barrett, S. (2003) 'The task of Irish health service reform', Irish Banking Review, December.

5. Wren, M. (2004) 'Health spending and the black hole', working paper, Economic and Social Research Institute, Dublin.

6. Wiley, M. (1998) 'Health expenditure trends in Ireland: past, present and future', in Leahy, A. L. and Wiley, M. M. (eds) The Irish Health System in the 21st Century, Oak Tree Press, Dublin.

7. Butler, M. and Boyle, R. (2000) 'Service planning in the health sector', CPMR discussion paper no. 13, Institute of Public Administration, Dublin

8. Tormey, B. (2003) A Cure for the Crisis: Irish Healthcare in Context, Blackwater Press, Dublin.

9. Irish Medical Organisation (2003) 'Current crisis in health can be stemmed', press release, 12th March.

10. Tussing, A. D. and Wren, M. (2005) The Health Report, Irish Congress of Trade Unions, Dublin.

11. As outlined in Government of Ireland (1996) Delivering Better Government: A Programme of Change for the Irish Civil Service, Second Report of the Co-ordinating Group of Secretaries, Stationery Office, Dublin.

12. Department of Health (1994) Shaping a Healthier Future: A Strategy for Effective Health Care in the 1990 s, Stationery Office, Dublin.

13. Ibid.

14. Department of Health (1996) [No.32.] Health (Amendment) (No. 3) Act [1996], Stationery Office, Dublin.

15. Department of Health (1998) Strategy Statement 1998-2001: Working for Health and WellBeing, Stationery Office, Dublin.

16. Department of Health, ref 14 above.

17. Department of Health \& Children (2001) Quality and Fairness: A Health System for You, Stationery Office, Dublin.

18. Ibid.

19. The Health Service Reform Programme (2003) is the culmination of the findings of two commissioned reports, namely Audit of Structures and Functions in the Health System (Prospectus Consultants) commissioned by the DOHC and Report of the Commission on Financial Management and Controls in the Health Service (Brennan) commissioned by the Department of Finance. The Hanly Report (2003), commissioned by the DOHC, is also seen as part of the reform programme in examining medical staffing and the reconfiguration of acute care nationally.

20. Department of Health \& Children (2004) [No.42.] Health Act [2004], Stationery Office, Dublin.

21. Ibid.

22. DOHC, ref. 17 above.

23. Butler and Boyle (2000), ref. 7 above

24. Mintzberg, H. (1979) The Structuring of Organisations, Prentice-Hall, Englewood Cliffs, NJ. 
25. Mintzberg, H. (1983) Structure in Fives: Designing Effective Organisations, Prentice-Hall, Englewood Cliffs, NJ.

26. Pettigrew, A., Ferlie, E. and McKee, L. (1992) Shaping Strategic Change. Making Change in Large Organisations: The Case of the National Health Service, Sage Publications, London.

27. McKevitt, D., Millar, M. and Keogan, J. F. (2000) 'The role of the citizen-client in performance measurement: the case of the street level public organisation (SLPO)', International Review of Administrative Sciences, Vol. 66, No. 2, pp. 619-636.

28. McKevitt, D. (1998) Managing Core Public Services, Blackwell Publications, Oxford.

29. Byers, V. (2007) 'Service planning and organisational change in the health sector: a study in control', unpublished $\mathrm{PhD}$ thesis, University of Limerick. Model developed and supervised by Dr David McKevitt.

30. Millar, M. and McKevitt, D. (2000) 'Accountability and performance measurement: an assessment of the Irish health care system', International Review of Administrative Sciences, Vol. 66, No. 2, pp. 285-296.

31. Denis, J. L., Langley, A. and Lozeau, D. (1995) 'The role and impact of formal strategic planning in public hospitals', Health Services Management Research, Vol. 8, No. 2, pp. 66-112.

32. Denis, J. L., Lamothe, L. and Langley, A. (2001) 'The dynamic of collective leadership and strategic change in pluralistic organisations', Academy of Management Journal, Vol. 44, No. 4, pp. $809-837$

33. Champagne, F., Contandriopoulos, A. P., Larouche, D., Clemenhagen, C. and Barbir, C. (1987) 'Strategic planning in hospitals - a health needs approach', Long Range Planning, Vol. 20, No. 3, pp. 77-83

34. McKevitt, D. (1990) Health Care Policy in Ireland: A Study in Control, Hibernian University Press, Dublin.

35. McKevitt (1998), ref. 28 above, p. 32.

36. Hogwood, B. and Gunn, L. (1984) Policy Analysis for the Real World, Oxford University Press, Oxford.

37. Walt, G. (1990) Health Policy: An Introduction to Process and Power, Witwatersrand University Press, Johannesburg.

38. Yin, R. (2003) Case Study Research: Design and Methods (3rd edn), Sage Publications, London.

39. In May 2006, nurses at the Irish Nurses Organisation annual conference passed a motion of no confidence in Minister Mary Harney. The nurses' motion blamed her for failing to deal with the trolley crisis and 'her negative attitude' towards nurses. A press release from the Irish Medical Organisation also called on Harney to end her antagonistic war of words; see: Irish Medical Organisation (2006) 'IMO calls on Tánaiste to end phony war', press release, 17th January.

40. Mintzberg, ref. 24 above.

41. Mintzberg, ref. 25 above.

42. Jacob, J. M. (1994) 'Lawyers go to hospital', in McKevitt, D. and Lawton, A. (eds) Public Sector Management: Theory, Critique and Practice, Sage Publications, London.

43. Maddock, S. (2002) 'Making modernisation work: new narratives, change strategies and people management in the public sector', International Journal of Public Sector Management, Vol. 15, No. 1 , pp. $13-43$.

44. McKevitt, ref. 34 above, p. 74.

45. Wrigley, L. (1990) 'Foreword' in McKevitt, D. (1990) Health Care Policy in Ireland, Hibernian University Press, Dublin. p. iv.

46. Health Consumer Powerhouse (2006) Euro Health Consumer Index 2006. This report measured the user-friendliness of European healthcare systems based on a set of indicators such as waiting times, patients' rights, outcomes, provision levels etc. Ireland came 25th out of 26 countries, with only Lithuania scoring lower. Severe waiting lists were cited as a problem (p. 20).

47. Grofman, B. (1997) 'Arend Lijphart and the "New Institutionalism", Centre for the Study of Democracy, paper 97-05, University of California, Irvine, CA.

48. Johnson, G. and Scholes, K. (2002) Exploring Corporate Strategy: Text and Cases (6th edn), Pearson Education, Edinburgh, p. 13. 


\section{Author Queries-MMH056}

Q1 Please confirm full contact details

Q2 Please note that references have been reworked according to journal style - please read through carefully

Q3 Please clarify

Q4 Please add URL/accessed date of press release - if available

Q5 Ref 2: "Stationery Office, Dublin" added - ok?

Q6 Ref 4: Please add date of publication (or vol/issue number) + page extent

Q7 Please add page extent

Q8 Ref 46: Please add publisher/city of publication 